\title{
MOBILE LEARNING: INNOVATION IN TEACHING AND LEARNING USING TELEGRAM
}

\author{
Zanaton H. Iksan', Sumaiyah Mohd. Saufian ${ }^{1}$ \\ ${ }^{1}$ Universiti Kebangsaan Malaysia, Malaysia \\ Corresponding email: zanaton.iksan@ukm.edu.my
}

\begin{abstract}
Innovation in teaching and learning is always done by the teachers to solve the problems. Teachers could use the latest education tools as their innovation. Attendance and students' engagement are the problems in a class and it could be overcome by using mobile learning as a teaching approach. In this case, Telegram is a tool for mobile learning. The aim of this study was to explore how Telegrams could be used in teaching and learning process. This study involved a case study approach where 31 students were the participants in the post graduate courses "Science Education and Human Development". Data were collected by Telegram discussion. This study found that several techniques can be carried out using Telegram: attendance, one way discussions, technique 1-2-3 discussion, pictures, drawing, and audio. Students responded that the teaching and learning using Telegram allow them to gain new experience, be more creative, generate spontaneous ideas, provide authentic ideas without the risk of being humiliated and encourage them to be excited as well as passionate with their learning. Compared with normal classes, all students can give ideas and the ideas were honest by themselves. This study implies that the latest innovation could solve the teaching according to the problems faced by teachers.
\end{abstract}

Keywords: Mobile learning, innovation, Telegram, teaching, learning.

DOI: http://dx.doi.org/10.20961/ijpte.v1i1.5120 


\section{INTRODUCTION}

The development of information and communication technologies (ICT) nowadays demands all educational institutions to keep pace with the progress. One of the efforts is to integrate the development of ICT in teaching and learning in higher education institutions. Over the decades, the learning system has been constantly improved by introducing distance learning to enable students who are in different geographical locations to continue their studies at university level. This system was later improved with advances in ICT through online learning, also known as e-learning. Today, with advances in communications equipment such as laptops, smartphones and tablets that are affordable for all society, it has once again provided a touch of ICT in education system through mobile learning (Siraj, 2004). Thus, education at the tertiary level also demands changes and innovations made in the process of teaching and learning to the development of teaching can be done in tandem with high-impact research.

Courses for the graduate program usually consist of full-time and part-time students. Attendance problems that do not reach $100 \%$ often arise due to a variety of students' background. Most students who are teachers in served are sometimes faced with the constraints of official duties at school. In addition, the geographical location also played a role in this problem because there are part-time students who come from areas as far as Pahang, Tanjung Karang and Melaka. Therefore, the implementation of mobile learning is well suited for the class which has geographically demographic range of students, as it could contribute to $100 \%$ of attendance of students, each time the class is held.

Apart from that, $100 \%$ of students' involvement has been found to be unachievable in face-to-face classes due to various factors such as the confidence level of students, lack of preparation and time constraints. However, with mobile learning method, it can ensure that $100 \%$ of the students are willing to be involved and engaged in the learning process than usual face-to-face classes on campus. Thus, this study aims to explore how the Telegram can be used in teaching and learning process.

\section{MOBILE LEARNING}

Mobile learning is a learning platform that uses mobile communication devices such as mobile phones, iPad, Personal Digital Assistants (PDAs) and tablet PC (Nawi, Hamzah, \& Abdul Rahim, 2015). Mobile learning allows students to experience the learning process at anytime and anywhere (Sharples, Taylor, \& Vavoula, 2007). Mobile learning also has the potential to be used as a teaching and learning tool when the class consists of students coming from different geographical areas and foster collaborative learning (Taleba \& Sohrabi, 2012). Learning through this method is also an alternative for face-to-face lecture in campus (Abas, Peng, \& Mansor, 2009). Aliff, Mohd Isa and Azwin Arif 2015 (Nawi et al., 2015) stated that mobile learning is one of the developments of teaching and learning which offers teachers and students to a more flexible and mobile as well as to create a spontaneous, informal, and privacy without ignoring the context of learning (Ally, 2009). 


\section{Mobile Learning using Telegram}

The use of communication devices such as mobile phones, tablets and laptops to access the internet has actually been frequently used as a means of connecting the teaching and learning process indirectly. Every course in university usually sets up a 'group' in WhatsApp or Telegram. Through this medium, students and lecturers are often engaged on an issue related to the course. Thus, indirectly, informal learning has occurred. In this study, the Telegram application has been selected to serve as a platform for mobile learning because of the conveniences it offers. For instance, the application is easy to be downloaded for free from the Play Store by the Android users. Telegram is not just easy to be handled but it can also give users the option to access it through any types of communication devices such as smartphones, tablets and computers. It also enables them to upload documents, images, audio and videos.

Furthermore, unlike WhatsApp, all members in the Telegram group serves as admin and they have the liberty to add other members to the group, in no time. This application can also be accessed using computers which thus makes it more flexible to users who want a larger display than a smartphone. This article will discuss how Telegram is used as a platform for mobile learning in courses of Science Education and Human Development (GC6023). This course was formally conducted in face-to-face class campus but mobile learning was carried out twice along the semester to see the response of students to innovation in teaching and learning.

\section{Theory of Constructivism}

In mobile learning, teachers act as facilitators, while students should be completely involved in the process of teaching and learning. Instructors should begin the learning process by proposing an open question which is followed by the students responding spontaneously and directed. Students will give an argument based on their perspective until it forms a new knowledge. The learning process is in line with the theory of constructivism in which students acquire and develop their own knowledge. In this way, knowledge is not just spread by individuals or teachers (Husin \& Abdul Azis, 2004). Constructivist approach also seeks to change passive to active learning environment where students are exposed to the open-ended questions that require them to think at higher levels.

\section{METHODOLOGY}

Teaching and learning processes using Telegram was done twice during the semester (14 weeks), in the course of Science Education and Human Development (GC6023). The study involved 31 students who enrolled in this course. Most of the students as participants in this study are 68\% part-timers while $32 \%$ are full-time students. As many as $74 \%$ of the students were either school or college teachers who were still in service while $26 \%$ were not. Teaching and learning using Telegram was held for one hour for each session. 
Data were largely collected through observation, interviews and document analysis from the conversations held in the Telegram class. Therefore, all conversations between lecturer and students in the Telegram class which was in the form of text were taken out to be analysed. This study focuses on how the Telegram is used in teaching and learning process and students' feedback on the implementation of mobile learning using Telegram.

\section{FINDINGS AND DISCUSSION}

Based on the analysis of teaching and learning using Telegram, the findings are divided into the techniques used and the students' feedback.

Generally, mobile learning using Telegram is an innovation in teaching and learning that should be implemented in institutions of higher education. Besides being able to contribute in solving the problem of students' attendance, this method can also ensure an active participation of all students during the mobile classrooms. In addition, mobile learning by Telegram is flexible to teachers and students based on the feedback collected from the participants. Feedback of participants also shows that the use of mobile learning Telegram gives new experience as it is creative, interesting and spontaneous. Participants also stated that they enjoyed learning through Telegram because they felt more relaxed and were comfortable to be actively involved in sharing their honest point of view.

\section{The technique used in the process of teaching and learning using Telegram}

The findings showed that there are various techniques used in teaching and learning usingTelegram. These techniques include the processes of before, during and after the teaching.

Before teaching, two things were emphasized, namely the provision of materials and the chosen of conducive environment for the learning process. The lecturer will state the materials that are going to be used during the lessons. Lecturer will also inform the students about the topics that will be discussed in the Telegram class. Therefore, students need to collect various materials such as books, articles and pictures to be used as a reference during the discussion.

Next, students should prepare a conducive atmosphere for learning process which involves both mental and physical. Students were asked to allocate one hour for the Telegram class to be held. Therefore, students must ensure that all matters and obligations have been settled in order to ensure the teaching and learning process is not influenced by their environment. Among the things that should be done is to ensure that the location is accessible to internet connection, people around already know that students are 'attending' the Telegram class and the communication device such as smart phones or computers get the continuous power supply to prevent distraction during class.

Several techniques are performed in the learning process. First, is the attendance taking. Contrary to face-to-face class, the process of taking attendance in Telegram class is faster because it only takes one to two minutes after the lecturer announced to report attendance. It was found that all students can attend even if 
they are located in different areas for instance in the dormitory, library, home and in a moving vehicle.

A total of $65 \%$ of students were at home, $16 \%$ were in hostels, $13 \%$ in the faculty, $3 \%$ in the library and $3 \%$ were in bus to led Selangor state contingents to the National Gymnastics Championships in Johor.The lecturer was also abroad during the time the Telegram class was held. However, the geographical location did not limit the learning process, as it was apparent that the Telegram class offered flexibility and convenience to teachers and students as well as ensuring $100 \%$ of students' attendance at that time.

For next technique, the learning process started with open questions posed by the lecturer. Students answered the questions by typing their ideas spontaneously with the supporting materials that have been prepared before the class began. In this case, there are possibilities of copying ideas among students to occur but it can be avoided by using 1-2-3 techniques. Students are given three minutes to think and type their answers. After three minutes, lecturer will type 1,2 and 3. Once the students see number 3, they will post the answer simultaneously. This process takes about 10 minutes. In addition, this technique can ensure that each student give their genuine ideas because they are not allowed to read others' ideas while thinking and typing their point of view.

Another technique is technique of Diagram, Mapping, Audio, and Caps Lock. Technique of Diagram is used by posting the pictures taken and discussing it. Mapping technique is used by students to reflect students' ideas about their views on a topic. In this study, the students drew a diagram mapping that was relevant to the activities performed by the school to achieve the school's vision of producing students with a scientific mind and value. However, sometimes the mapping drawn by the students can be difficult to be understood. Therefore, for further elaboration, students can use the audio technique by recording their voice and send it to the Telegram class.

Caps Lock technique can be used to differentiate the lecturer's writing from the students'. When students are eager to type and send their responses, the lecturer's writing will sink together with the students' responses. Thus, the uppercase letter can only be used by lecturer to ease the students to scroll up while looking for open questions posed by the lecturer.

\section{Students feedback related to learning using Telegram}

Student's feedback towards mobile learning has been requested as soon as the learning session ended. Studies have found a total of ten survey participants stated that learning using Telegram is interesting. Some of the responses are '... interesting ... didn't realize the time passes..' and '..an interesting process of teaching and learning that can improve the active responses in teaching and learning session'. This learning process was carried out for an hour and they did not realize the time was up due to their active involvement in giving and reading feedback.

There were also study participants who said that they enjoyed learning using Telegram. Feedback of survey participants also infused with icons that showed 
their emotions like smile and happy face after undergoing such Telegram class. Among their responses are ' $I$ feel good because it is more relaxing ... just cannot catch up to read what other friends posted..but it is okay because I can scroll up to read them..hehehe' and 'It's fun, so do not realize the time has passed for an hour'.

There were study participants who said learning using Telegram encouraged them to give opinion confidently. Contrary to face-to-face classes, not all students are able to express their ideas and opinions especially when it comes to personal matters. However, in this Telegram class, all students successfully expressed their opinions confidently. Quotes regarding these students are 'This class is fun.. all can express ideas without shame' and 'I like this kind of class, teachers can express their hearts and thoughts without feeling shy'.

Study participants stated that learning is more relaxed as they responded with: 'Very relaxing and fun' and 'Learning become more relaxing and interesting'. These show that the students do not feel pressured even though there were a lot of things to be thought and written in a short time.

In addition, there were students who responded that learning using Telegram gave them the opportunity to be creative, as the following quote '..It is a creative way'. This creativity can be seen when the students need to sketch their ideas in various forms such as mapping, flow charts, and pictures and so on.

Studies showed that through the use of Telegram, all students can participate actively and are able to know others' thoughts, as according to the following quote: 'I enjoyed learning like this as I can know the thoughts of all members in the class. Compared to regular classes, not everyone will speak' and ' ... can increase the active response in the teaching and learning session'.

In the meantime, mobile learning using Telegram is also flexible based on the feedback from two of the study participants. Study participants indicated that she was on the bus to Johor to lead the Selangor contingent to the gymnastics competition. This situation showed that the Telegram class can be done regardless of students' whereabouts. Students also responded 'Class today is very relaxed and flexible ... though not face to face but the goal is to gain knowledge. Learn a lot today. I actually am in Johor. In the bus. Bring the Selangor contingent MSSM gymnastics'.

While the Telegram class was being held, there was a student who 'arrived' late to class. However, the student said that because of Telegram, she could still follow the previous discussion by reading the conversation from the beginning of the class and responded to the open questions posed by the lecturer. Compared with normal face-to-face class, when students arrive late to class, students had to borrow notes from other friends to catch up with the topics that have been discussed since the beginning of the class. This was expressed by a student, such as the following passage:

'Even though I was late and friends are begining to wrap up, I am still able to follow what was discussed in class by reading back the conversation before. In addition, I can also give my answers and thoughts to be read by other friends. 
Unlike a regular classroom, when I arrived late, I would not know what was discussed previously and had to borrow a notebook form friends to copy the important contents discussed'.

Mobile learning using Telegram also provides a space for students to give ideas spontaneously. This is because the students do not know in advance about the questions that will be posed by the lecturers. In this way, students will think actively and answer questions based on their perspective and existing knowledge. The following excerpt illustrates this point, 'It is a fun and spontaneous learning. Because the brain is suddenly active in this evening. This way everyone gives their opinion compare to face-to-face class'.

Mobile learning is a new learning method which gave a positive impact, according to some study participants. Students' feedback on this subject is shown as the following quote: 'This class is suitable for sharing ideas. A new experience' and 'It's something new and give very positive impact ... thought this way can provide a positive impact in the students, I hope that this way of class can be disseminated as it has highly impacted me'. It was thought that this positive impact should be disseminated and shared with students and lecturers in other courses so that others too can experience the excitement of learning by using Telegram.

Another quite interesting matter to be featured in this study is that the study participants were able to give their honest views as the following excerpt: ' $A$ relaxing and interesting learning. A more honest view'. Among the objectives to be achieved is that students should be aware of how far they had been trying through various approaches and activities in order to generate school students who have scientific skills and values. Hence they should reflect and express themselves by recording their voice. During the voice recording, they were alone and there was nobody around who could hear them. Thus, they were able to sincerely express their ideas despite the fact they actually know that the recording will be heard by the lecturer and classmates.

\section{CONCLUSION}

Mobile learning using Telegram gave positive impacts on participants in the study because they were required to record an audio on their opinion as a teacher to apply the values among students. Through the audio recorded in the Telegram, all students can share the values that should be nurtured within them as well as their hope and resolution as an educator. Mobile learning can also ensure that students are always ready prior to the lesson and are $100 \%$ focus during the conducted classes. Contrary with face-to-face lecture, students can lose focus when the lecturer is teaching. Mobile learning using Telegram is more contextual and significant because in the end of the process of teaching and learning, all students can achieve the learning objectives. These positives impacts cannot be fully guaranteed if the study was conducted in an regular face-to-face lecture. 


\section{REFERENCES}

Abas, Z. W., Peng, C. L., \& Mansor, N. (2009). A study on learner readiness for mobile learning at Open University Malaysia. In International Conference Mobile Learning (IADIS).

Ally, M. (2009). Mobile learning: Transforming the delivery of education and training. Athabasca: Athabasca Universit Press.

Husin, K., \& Abdul Azis, S. H. (2004). Pedagogi Asas Pendidikan. Pedagogi Asas Pendidikan. Kuala Lumpur: Kayazano Enterprise.

Nawi, A., Hamzah, M. I., \& Abdul Rahim, A. A. (2015). Teachers Acceptance of Mobile Learning for Teaching and Learning in Islamic Education: A Preliminary Study. Turkish Journal of Distance Education, 16(1).

Sharples, M., Taylor, J., \& Vavoula, G. (2007). A Theory of Learning for the Mobile Age. (R. Andrews \& C. Haythornwaite, Eds.). London: The Sage Handbook of Learning Research.

Siraj, S. (2004). Pembelajaran Mobile dalam kurikulum masa depan. Masalah Pendidikan, 27, 128-142.

Taleba, Z., \& Sohrabi, A. (2012). Learning on The Move: The Use of Mobile Technology to Support Learning For University Students. In International Conference on Education and Educational Psychology (ICEEPSY). 